\title{
Memories of Professor Gian Paolo Pessina
}

\section{Luana Paulesu}

\section{Department of Life Sciences, University of Siena}

It is with deep emotion that I remember my friend and colleague Gianpaolo Pessina, Professor of Physiology at the University of Siena (Italy). We worked closely for many years and in different fields of research and were able to build a friendship that was soon extended to our families. I could say I grew scientifically thanks to his advice and the journey we made together for about 35 years, A long period that left me with many good memories. I am sure that everyone who met Gian Paolo, remembers his beautiful smile that inspired friendship and sympathy. He was a good-natur, open person and had a good character. He was a good friend. I cannot forget when, in the 70s, I was entrusted to his guidance as a young graduate. From him, I soon learned the enthusiasm for research and the strength to go on without complaining about failures. Gian Paolo was, in fact, full of enthusiasm and never complained. My first steps into the world of research, under the guidance of Gian Paolo have been important for my work life and I am deeply grateful to him. I remember that the first important scientific topic Gian Paolo studied was the aging of erythrocytes. In particular, he studied the changes occurring in erythrocytes in the course of their life that make these cells look older. He was able to show that these cells lose fragments of molecules from their exterior face, as they age. Among other molecules Gian Paolo indicated that the sialic acid peels off from the cell membrane as the cell grew older. As mentioned, Gian Paolo spent a lot of energy on this research area and produced important publications for international scientific journals. His research then evolved on different issues. Gian Paolo gave a great contribution to the knowledge of the metabolism and pharmacokinetics of the cytokines, molecules that play a role of defense against pathogens but are also natural regulators of cellular physiological processes. Another important issue Gian Paolo studied was the action of cytokines in preserving the physiological conditions under exposure to risk factors. Among the factors potentially interfering with the physiological processes, Gian Paolo first studied the effect of cigarette smoking, and subsequently, the effect of electromagnetic waves. Since the 90s, Gian Paolo began working on this latter issue, publishing a series of articles first on the effects that electromagnetic waves have on the cells of the immune system and, later, on the central nervous system, demonstrating that these waves produce changes in cell membranes leading to a change in the processes of transport of calcium and effects on cell proliferation. Gian Paolo also held many institutional duties at the University of Siena: he was the Director of the Institute of General Physiology and Nutritional Science, Faculty of Pharmacy and subsequently, of the Department of Physiology of the three Faculties, Pharmacy, Science and Medicine. He was the Director of the PhD, then of the Graduate School, done in conjunction with colleagues pharmacologists. At the time of his death, he was the President of the Committee for the teaching of the Master of Science in Pharmaceutical Chemistry and Technology.

For many of these institutional activities and research I found myself often working with Professor Pessina, always in mutual respect and friendship.

Friendship is the magic word to describe him, Gian Paolo Pessina. His friends, within and outside work, together with his family, were the framework of his life. He had many friends in Grosseto, his home town close to the sea he loved and the place of his family's traditional pastry ands ice cream shop. He used to spend his free time by the sea in Principina, just near Grosseto. His greatest joy was to bring friends with his boat to the "Formiche", small islands, almost rocks, within the Tuscan archipelago. For his ability to relate to others and the respect he had for anyone, Gian Paolo was the connection between friends, colleagues in the Department, Faculty, and members of the Physiological Society of Italy.

And finally, I cannot forget to mention his hobby: producing his own red wine and the so-called vin santo, a sweet wine for his friends.

I would like to greet him saying thank you, for walking with us and giving us an example of true friendship, devotion to duty and great enthusiasm for scientific research. 